\title{
ANÁLISE COMPARATIVA DO CONTEÚDO FILO MOLLUSCA EM LIVRO DIDÁTICO E APOSTILAS DO ENSINO MÉDIO DE CASCAVEL, PARANÁ
}

\author{
Comparative analysis of the Phylum Mollusca contents \\ in a High School instructional book and in teacher's \\ notes/handouts at Cascavel, Paraná, Brazil
}

\author{
Juliana Cristina dos Santos ${ }^{1}$ \\ Luis Francisco Angeli Alves ${ }^{1,2}$ \\ João Jorge Corrêa ${ }^{3}$ \\ Everton Ricardi Lozano Silva ${ }^{4}$
}

\begin{abstract}
Resumo: O objetivo deste trabalho foi realizar uma análise comparativa entre um livro didático de Biologia utilizado na terceira série do Ensino Médio, da rede estadual de ensino do município de Cascavel, PR, e apostilas utilizadas por duas escolas da rede privada. Após o levantamento e escolha, os materiais didáticos foram submetidos a uma análise geral em relação à capa, encadernação, espaçamento entre linhas, tamanho da letra, ilustrações, quadros e tabelas, e, também, a uma análise específica do conteúdo Filo Mollusca, considerando-se conceitos; sugestões de leituras complementares; erros ortográficos e conceituais; erros de impressão e revisão; ilustrações. Verificou-se que todos os materiais didáticos analisados apresentam falhas. No entanto, em umas das apostilas, foram encontradas mais falhas, pois além do seu conteúdo ser extremamente sucinto e não apresentar um planejamento em relação às atividades propostas, continha imagens incorretas e sem legendas auto-explicativas.
\end{abstract}

Palavras-chave: Material didático. Filo Mollusca. Qualidade. Ensino de zoologia.

\begin{abstract}
The objective of this work was to carry out a comparative analysis between an instructional Biology book used in the junior year of high school in the school network system of the State of Parana at the municipality of Cascavel, PR, and teacher's notes/handouts used by two schools in the private school network. After surveying and selecting the materials, these were submitted to a general analysis with regard to their cover, binding, line spacing, font size, illustrations, charts and tables, and also to a specific analysis in relation to their Phylum Mollusca contents, in which concepts, supplementary reading suggestions, typos and conceptual errors, printing and proofreading errors, and illustrations were taken into consideration. It was observed that all learning materials analyzed showed imperfections; however, a higher number of imperfections was found in one set of teacher's notes, because besides having an extremely succinct content and not presenting any planning in relation to the proposed activities, it contained incorrect images without self-explanatory labels.
\end{abstract}

Key words: Learning materials. Phylum Mollusca. Quality. Zoology teaching.

\footnotetext{
${ }^{1}$ Bióloga; mestranda, Programa de Pós-graduação em Entomologia, Universidade Federal de Viçosa (UFV). Viçosa, MG. <bioentomologic@yahoo.com.br>

${ }^{2}$ Doutor em Entomologia; professor adjunto, Centro de Ciências Biológicas e da Saúde, campus de Cascavel, Universidade Estadual do Oeste do Paraná (UNIOESTE); bolsista de produtividade em pesquisa/CNPq. Cascavel, PR.<faalves@unioeste.br>

${ }^{3}$ Doutor em Educação; professor adjunto, Curso de Pedagogia, Universidade Estadual do Oeste do Paraná (UNIOESTE). Cascavel, PR. <jjcorrea@brturbo.com.br>

${ }^{4}$ Biólogo; doutorando; professor, Curso de Pedagogia, União Pan Americana de Ensino. Cascavel, PR. <evertonloz@hotmail.com>
}

${ }^{1}$ Rua Cristóvão Longuinho Santana, 135, ap. 101

Bairro Fátima - Viçosa, MG

36.570-000 
Santos, J. C. et al.

\section{Introdução}

A educação brasileira vem, por meio da legislação de políticas públicas específicas para este fim, sistematicamente seguindo uma tendência mundial, estabelecendo vínculo direto com o mercado de trabalho, acompanhando as mudanças sociais, políticas e econômicas, bem como as exigências de um mercado cada vez mais exigente e rigoroso com a organização do próprio processo de trabalho.

O ensino, por sua vez, esteve por muito tempo vinculado à elite brasileira. As classes menos favorecidas não tinham grandes chances de acesso ao âmbito escolar, sendo basicamente compostas por pessoas leigas ou semi-analfabetas, destituídas de um caráter crítico para discernir sobre o que lhes eram imposto pela ordem vigente.

Entretanto, com as mudanças ocorridas no setor educacional, sobretudo na década de 1970, houve uma crescente demanda de alunos no Ensino Médio. Porém o Ensino Superior não acompanhou tal crescimento, de forma que, frente à escassez de vagas para todos, houve a implantação do vestibular classificatório, uma tentativa de dar oportunidade a qualquer aluno, independente da classe social, de freqüentar o Ensino Superior público e gratuito.

De forma paralela, verificou-se uma expansão das escolas privadas, as quais prometiam oferecer um ensino de melhor qualidade, caracterizando o Ensino Médio como uma etapa preparatória para tornar o aluno apto para competir por uma vaga no concurso vestibular. Esta mudança foi acompanhada de uma inovação no sistema educacional, pois, na maioria das escolas, as apostilas didáticas substituíram o tradicional livro didático, com o objetivo de se ter um material adaptado ao sistema de vestibular, com informações sintetizadas e formatadas às provas. Assim, as apostilas são consideradas o marco da moderna Indústria Cultural, sendo vistas como um símbolo de eficiência e modernização, promovendo certo "status" para instituições particulares de ensino, o qual passa a ser caracterizado como um ensino de "grife" e muito utilizado no apelo comercial, na forma de "slogan".

Tanto apostilas como livros didáticos do Ensino Médio apresentam os conteúdos das matérias básicas, tais como: Física, Química, Português, Biologia, Geografia, História, entre outras disciplinas.

Atualmente, a Biologia apresenta um papel relevante, pois além de estar inserida no cotidiano, as descobertas científicas e os avanços tecnológicos estão presentes nos diversos meios de comunicação. Assim, seu estudo deve proporcionar, aos alunos, o desenvolvimento do caráter investigativo de atividades científicas e, também, tornar o indivíduo mais crítico, capaz de interpretar e tomar decisões.

O material didático - em especial, o livro e apostila - é um dos principais recursos utilizados, pelos professores, no seu trabalho diário de preparação de aulas; e, para os alunos, é uma das únicas fontes de pesquisa e estudo. E, dada a ausência de uma análise oficial, pelo Ministério da Educação, até o ano de 2005, para este material referente ao Ensino Médio, torna-se de suma importância sua análise, visando à melhoria da qualidade do mesmo, referente à forma de estruturação e apresentação dos conteúdos. Sendo assim, o objetivo deste trabalho foi realizar uma análise geral qualitativa do material didático, e específica do conteúdo Filo Mollusca, em livro didático e apostilas utilizadas por alunos do Ensino Médio de escolas públicas e particulares do município de Cascavel, PR. 


\section{Metodologia}

No ano de 2005, foi realizado um levantamento, junto ao Núcleo Regional de Educação no município de Cascavel, PR, para a verificação das escolas com maior número de alunos matriculados. Em seguida, buscou-se saber, diretamente com o coordenador pedagógico ou a secretaria das escolas selecionadas, qual o livro didático utilizado nas mesmas.

Da mesma forma, procuraram-se essas informações nas instituições particulares, porém as mesmas não foram disponibilizadas. Em virtude disso, foram selecionados dois colégios, dentre os mais tradicionais da rede particular de ensino, que utilizavam sistemas apostilados distintos.

O material didático indicado foi comparativamente analisado, verificando-se capa e encadernação, espaço entre linhas, tamanho da letra, ilustrações, quadros e tabelas (1 análise geral). Efetuou-se, também, uma análise do conteúdo do Filo Mollusca, com base na adequação e atualização dos conceitos, contextualização, sugestões de leituras complementares, erros ortográficos, de impressão e revisão e ilustrações (2 análise específica). A análise foi realizada com base em uma ficha de avaliação, proposta por Lima (1984), e adaptada por Silva (2002), para a elaboração e avaliação de manuais escolares (Anexo 1).

Como base para as respectivas análises, utilizou-se o livro Zoologia de Invertebrados (RUPPERT e BARNES, 1996), um dos livros mais conceituados da área.

\section{Resultados e discussão}

Verificou-se que, das seis escolas estaduais, apenas duas adotam livro didático de Biologia no Ensino Médio, o livro "Fundamentos da Biologia Moderna" (AMABIS e MARTHO, 2002), o qual, posteriormente, passou a constar como Título Recomendado na Avaliação do Livro didático do Componente Curricular de Biologia, realizada no âmbito do Programa Nacional do Livro para o Ensino Médio - PNLEM/2007 (BRASIL, 2006).

Em relação às instituições particulares, duas apostilas foram selecionadas, sendo uma do Sistema Positivo 2005 (apostila A) e outra do Sistema Objetivo 2005 (apostila B).

\section{1) Análise geral}

A capa é apresentada de diferentes formas nos respectivos materiais analisados, e todos os materiais analisados apresentam imagens nítidas e coloridas, despertando a atenção visual dos alunos para a capa.

O livro didático apresenta encadernação em forma de brochura e as apostilas, em espiral. Ambos são de material resistente, facilitando o uso e manuseio por tempo prolongado.

Em todos os materiais analisados, o texto possui espaçamento entre linhas e tamanho de letra que permite claramente a visualização e leitura do texto, porém, em relação à hierarquização de títulos e subtítulos, a apostila A é o material que se apresenta menos estruturado neste aspecto, se comparado com os outros materiais analisados.

Vale ressaltar que um dos critérios apontados na avaliação do Plano Nacional do Livro Didático do Ensino Básico (PNDL/99), realizado pelo MEC, é o aspecto visual. Dentro 
desse tópico, deve ser analisada a presença de títulos e subtítulos, os quais devem se apresentar de forma hierarquizada, evidenciada por recursos gráficos. Além disso, desenhos, espaçamento entre letras, palavras e linhas devem atender à legibilidade e ao nível em que o livro se destina (BRASIL, 2000).

O livro didático apresenta poucas fotografias e ilustrações, porém, são claras, didáticas e de boa qualidade gráfica quanto ao tamanho, às cores e à definição. Além disso, as legendas são explicativas, possibilitando, ao aluno, compreender o texto com o auxílio da ilustração. Tal fato, entretanto, não se verifica nas apostilas: embora elas não apresentem imagens de qualidade, estas estão presentes em maior número, retratando com mais detalhe o Filo estudado.

Com relação ao texto, o livro didático apresenta um quadro comparativo que aborda aspectos do hábito alimentar, habitat, principais representantes do Filo, morfologia corpórea, etc. Tal organização facilita, ao aluno, a visualização ampla de todo conteúdo a ser estudado de forma comparada. Ao contrário, nas apostilas, os quadros estão ausentes, sendo que elas retratam cada classe com um resumo das explicações teóricas, e, conjuntamente, imagens.

Com referência aos textos complementares, não constam em nenhum dos materiais analisados, dentro do conteúdo abordado. Tal fato pode ser prejudicial ao aprendizado, pois, conforme Bizzo (1996), a autonomia do aluno estaria sendo incentivada com a sugestão de leituras complementares, que seriam as fontes de recursos para a busca de maiores informações, ao passo que, também, propiciariam um aprofundamento do conteúdo estudado.

Entretanto, as apostilas apresentam sugestões de leituras complementares no material de apoio (cd-rom), porém, tais informações limitam-se apenas aos alunos que têm acesso a um microcomputador, fato nem sempre comum para a maioria dos alunos. Tal problema, algumas vezes, é contornado com o acesso aos equipamentos disponibilizados pela própria escola.

Em relação ás atividades complementares, o livro didático contém diversos exercícios, sendo que as primeiras questões (presentes no item "Conceitos fundamentais") são perguntas objetivas, seguidas de perguntas extraídas de exames vestibulares, que relacionam conceitos e fatos (também questões objetivas). Finalmente, vêm as perguntas de nível mais complexo, que fazem o aluno pensar e discutir criticamente (questões discursivas).

$\mathrm{Na}$ apostila $\mathrm{A}$, também são verificadas perguntas de diferentes níveis, sendo as primeiras de assimilação, seguidas das intermediárias, de aperfeiçoamento, e, as últimas, de aprofundamento do conteúdo, em um maior grau de complexidade. Todas as questões são objetivas e foram aplicadas em vestibulares anteriores. Contudo, este mesmo material também contém algumas questões discursivas. Isto demonstra a preocupação dos autores em fazer com que os alunos adquiram conhecimentos mais detalhados, partindo de um raciocínio mais simples, passando para níveis mais complexos. Além disso, possibilita ao aluno responder questões discursivas e treinar a organização de suas idéias, juntamente com o conteúdo trabalhado.

A apostila B apresenta apenas duas questões discursivas e três questões objetivas sobre o assunto tratado, caracterizando-se, neste critério, como material de baixa qualidade.

Quanto aos erros de digitação, de maneira geral, são raros, sendo o único caso verificado na apostila B, onde o termo caracol aparece grafado erroneamente como "carocol". 


\section{2) Análise específica}

\section{Apresentação do conteúdo}

O Filo Mollusca é apresentado de forma ordenada tanto no livro didático como na apostila $\mathrm{A}$, com uma pequena introdução relatando a origem do termo Mollusca e suas principais características e número de espécies descritas. A apostila B relata diretamente as características gerais do corpo dos moluscos, mencionando algumas classes, e também não traz informações sobre a quantidade de espécies descritas. Além disso, todos mencionam sobre a distribuição ecológica dos moluscos, relacionando-os ao ambiente marinho, com espécies pelágicas e outras de água doce ou salabora, e outras, ainda, que habitam ambiente úmidos.

Em relação ao habitat de cada classe, os materiais analisados apresentam falhas. No livro didático, verificou-se que os indivíduos pertencentes à classe Gastropoda são descritos como caramujos que vivem em água salgada e doce, o que é correto. Porém, ao apresentar a afirmação que caracóis e lesmas vivem em ambiente terrestre, essa informação passa a ser incompleta, pois há caracóis que vivem em ambiente marinho, água doce e ambiente terrestre úmido, e ainda lesmas em ambiente terrestre úmido e/ou marinho (RUPPERT e BARNES, 2005).

Nas apostilas, tais informações estão disponibilizadas de forma generalizada, afirmando-se que os representantes dessa classe podem ser encontrados tanto em ambientes aquáticos, quanto terrestres. A apostila A menciona que alguns representantes ocupam o ambiente terrestre, no entanto não relaciona essas espécies aos diferentes ambientes terrestres nos quais vivem, como regiões úmidas e secas, dando a impressão de que esses animais podem ser encontrados indistintamente em ambientes secos, o que não é fato.

Conforme constatado em Ruppert e Barnes (1996), os pulmonados terrestres acabam por perder muita água através da evaporação da trilha de limo deixada pelo animal ao se locomover, de forma que a maioria desses animais é adaptada apenas a ambientes úmidos, abrigados sob rochas, troncos ou em meio ao húmus e folhas no solo. Algumas espécies ainda habitam lugares secos e são ativas somente à noite, podendo também hibernar ou estivar.

\section{Classificação}

A classificação taxonômica adotada no livro didático está de acordo com a apresentada por Ruppert e Barnes (1996), alocando o Filo Mollusca após o filo Nematoda e antes do Filo Annellida. Porém, na seqüência em ambas as apostilas, o Filo Mollusca é apresentado antes do Filo Anellida, levando à conclusão de que tais materiais não enfatizam o grau de parentesco evolutivo existente entre os organismos estudados, baseado na segmentação corpórea, presente em anelídeos e artrópodes.

De acordo com Ruppert e Barnes (1996), o Filo Mollusca apresenta sete classes: Monoplacophora, Poliplacophora, Aplacophora, Scaphopoda, Bivalvia, Gastropoda e Cephalopoda. O livro didático apresenta uma explicação geral de cada classe em um quadro comparativo. No entanto, a classe Aplacophora encontra-se ausente, uma vez que é pouco conhecida, por se tratar de animais bentônicos, e apresentar, atualmente, apenas 288 espécies classificadas.

Das sete classes reconhecidas, a apostila A não menciona as classes Monoplacophora e Aplacophora, e, na apostila B, faltam as classes Monoplacophora, Aplacophora e Poliplacophora. 
Tanto no livro didático, quanto na apostila $\mathrm{A}$, os autores apresentam uma das classes como Bivalvia ou Pelecypoda, sendo que o termo Pelecypoda foi substituído por Bivalvia, porém, ainda usual. De acordo com Ruppert e Barnes (1996), são três as formas de denominação dessa classe: Bivalvia, Pelicypoda ou Lamellibranchia. Verificou-se, também, que a apostila B utiliza somente os termos desatualizados. Segundo Andrade (informação pessoal) ${ }^{5}$ os termos Pelicypoda e Lamellibranchia são considerados desatualizados.

Salienta-se que é importante e necessária a abordagem das diferentes nomenclaturas, atuais ou não, pois podem ser citadas em uma literatura e serem desconhecidas do aluno ou, ainda, podem ser adotadas em exame vestibular.

O mesmo é verificado para a classe Poliplacophora, que, na apostila A, é denominada de Amphineura, demonstrando a desatualização desse material didático, e, no livro didático, ambos os nomes são mencionados.

Seria adequado que o material didático apresentasse a origem da palavra, para que o aluno relacione com o significado do termo ou nome utilizado, e associe às características do grupo, tal como se vê nas apostilas: classe Gastropoda (gaster = estômago, ventre; podos = pés), Pelecypoda (pelekys = machado; podos = pés), Cephalopoda (kephale = cabeça; podos = pés), Amphineura $($ amphi $=$ duplo, neura $=$ nervos $)$, Scaphopoda $($ skaphe $=$ barco; podos $=$ pés $)$.

\section{Morfologia externa}

O livro didático apresenta informações teóricas da morfologia externa no quadro comparativo das classes abordadas, e algumas ilustrações, na introdução, referentes à evolução dos cefalópodes, bivalves e gastrópodes, a partir do ancestral hipotético, o qual vai originar grupos atuais, como os Cefalópodes, caracterizando, sobretudo, a diversidade morfológica. Contudo, não chama a atenção dos alunos para observar os principais representantes das classes descritas.

Ambas as apostilas tratam de cada classe separadamente, apresentando figuras que identificam as principais diferenças que existem entre estas, sendo desprovidas de legendas, dificultando, assim, a compreensão do leitor.

A apostila B, quando exemplifica a classe Bivalvia (Pelecypoda), apresenta duas imagens. Uma delas de maneira incorreta, pois a cabeça e concha são mostradas em espiral, semelhante a um gastrópode terrestre, sendo que os Bivalvia não portam cabeça e encéfalo, além disso, apresentam união dorsal de duas valvas, daí o termo Bivalves.

Certas incorreções denotam eventual displiscência em não consultar fontes atuais ou de respaldo científico (BIZZO, 1996). Ainda de acordo com a avaliação do PNDL de 1999 (Ensino Fundamental), apresentar erroneamente conceitos, imagens e informações fundamentais das disciplinas científicas em que se baseia, significa descumprir objetivos didáticopedagógicos (BRASIL, 2000).

${ }^{5}$ ANDRADE, G. S., professor doutor, Curso de Ciências Biológicas Unioeste, campus Cascavel. 
Além disso, conforme salienta Belmiro (2000), as imagens são de extrema importância para o aprendizado de Ciências e Biologia, e devem auxiliar no processo de entendimento do conteúdo, podendo também enriquecer a leitura do texto. Além disso, estas devem ser claras, objetivas, precisas, de fácil compreensão, podendo também intrigar, problematizar, convidar a pensar e despertar a curiosidade (BRASIL, 2000). Portanto, falhas dessa natureza, além de comprometerem o aprendizado, eventualmente, podem comprometer o aluno num exame vestibular, foco principal da sua proposta.

\section{Morfologia interna e fisiologia}

A morfologia interna e a fisiologia do grupo são apresentadas de forma similar nos materiais, sendo que os assuntos são fragmentados em tópicos referente a cada sistema.

A apostila A, além das explicações, apresenta figuras que ilustram cada sistema isoladamente, e, juntamente com a fisiologia interna, explora a morfologia externa. Tal fato possibilita ao aluno relacionar a posição dos sistemas e a morfologia corporal, facilitando o aprendizado. A apostila B apresenta, apenas, explicações teóricas, sem nenhuma imagem, ao passo que, no livro didático, as imagens presentes referem-se apenas ao sistema circulatório e reprodutor, ou seja, a falta de ilustrações, no decorrer do texto, dificulta a compreensão dos alunos sobre os processos fisiológicos, além de torná-lo cansativo.

Sistema digestório. Os moluscos apresentam uma grande variação morfológica, em virtude das diferentes formas de obtenção de alimento (filtradores, raspagem de superfícies com a rádula, e, ainda, animais que possuem um bico córneo, para captura e dilaceração de alimento).

Todos os materiais analisados citam a presença de um sistema digestório completo e presença de rádula em algumas espécies. A apostila $\mathrm{A}$ menciona apenas que bivalves não portam rádula, e, embora correta, está incompleta, uma vez que os bivalves utilizam brânquias, tanto para as trocas gasosas, como, também, para filtração da água para a captação de alimento.

Essa relação entre a filtração e a captação de alimento é apresentada na apostila B, a qual também cita alguns exemplares de animais filtradores e não filtradores, e o tipo de alimento obtido. Além disso, ambas as apostilas não mencionam que, nos cefalópodes, a rádula pode ser reduzida ou ausente, ou, ainda, que alguns exemplares destes portam uma mandíbula quitinosa, como observado no livro didático.

A abordagem a respeito do hábito alimentar da classe Gastrophoda e Poliplacophora é feita no livro didático apenas no quadro comparativo, trazendo apenas a informação de que estes animais raspam o alimento da superfície em que vivem, sem esclarecer que isto é feito com a rádula.

Sistema respiratório. O livro didático especifica apenas dois tipos: pulmonar e branquial, citando as principais espécies e os processos para a realização das trocas gasosas, sendo que as apostilas mencionam outras formas de respiração. Contudo, a apostila A apenas cita que a respiração pulmonar está presente em gastrópodes terrestres, a branquial na maioria dos aquáticos, e a cutânea em alguns moluscos aquáticos; e a apostila B explica sobre a localização do pulmão e das brânquias no corpo do animal. Mesmo explicando sobre tal localização, comete falhas, uma vez que não apresenta nenhuma figura possibilitando a visualização de tais 
estruturas. Conforme discutido anteriormente, as figuras são de grande importância no processo de entendimento do conteúdo, devendo ser, além de presentes, claras e objetivas.

Ambas as apostilas cometem falhas semelhantes, ao mencionarem que os gastrópodes terrestres respiram apenas por pulmões, quando nem todos são pulmonados, existindo espécies de caracóis terrestres que respiram por brânquias (RUPPERT e BARNES, 1996). Além disso, há erros quanto à respiração cutânea, pois embora seja afirmado, na apostila $\mathrm{A}$, que é restrita aos moluscos aquáticos, existem exceções.

Sistema circulatório. No livro didático, este é exemplificado ilustrativamente, de uma maneira fácil de ser compreendida, possibilitando ao aluno diferenciar um sistema circulatório aberto de um fechado; porém, a esquematização está isolada e generalizada, não sendo relacionada morfofisiologicamente a nenhum representante do Filo.

Tanto o livro didático quanto a apostila $\mathrm{A}$, quando mencionam o sistema circulatório fechado, abordam os cefalópodes como o principal exemplo, devido a estes apresentarem estruturas mais complexas que os outros grupos de moluscos, sendo que a apostila A é o único material didático a mencionar sobre a presença de pigmentos respiratórios em molusco (hemocianina e hemoglobina).

Entretanto, a apostila B, equivocadamente, menciona que todas as classes de moluscos apresentam sistema circulatório aberto ou sistema lacunar.

Sistema excretor. A apostila A apresenta uma explicação geral do processo de filtração e uma figura esquematizando a câmara pericárdica, nefrídios e o poro excretor. Porém, a figura é de difícil compreensão, pois é apresentada de forma isolada, sem relação com o corpo do animal. Tal fato, demanda uma atenção maior por parte do professor na correlação, pois se a mesma não ocorrer, torna-se inútil para fins didáticos.

Por sua vez, o livro didático apresenta uma explicação teórica muito semelhante à apostila A, enquanto a apostila B apresenta informações muito sucintas, citando apenas que o sistema excretor é formado por nefrídeos. Contudo, o livro didático e a apostila B não apresentam ilustrações referentes ao sistema excretor.

A apostila A é o único material didático que cita a amônia como um dos principais produtos de excreção. Contudo, segundo Ruppert e Barnes (1996), a maioria dos gastrópodes aquáticos excreta amônia e algumas espécies terrestres convertem amônia em ácido úrico. Esta informação é importante, pois os produtos de excreção ou resíduos metabólicos gerados no sistema excretor têm relação com o habitat onde os animais são encontrados, e representa uma adaptação à vida terrestre.

Sistema nervoso. Nos moluscos, é do tipo ganglionar, sendo que as apostilas citam três principais glânglios presentes (cerebral, podal e visceral). Mas apenas a apostila A explica que o sistema nervoso é descentralizado na maioria dos moluscos, e centralizado apenas em cefalópodes, nos quais os órgãos do sentido são mais desenvolvidos. A apostila B, além dos três tipos ganglionares, menciona apenas quais são os elementos sensoriais, tais como: olhos, estatocistos, células tácteis e quimioceptores. Nota-se que as informações apresentam-se de maneira muito resumida.

Já o livro didático, traz a informação de que o sistema nervoso é mais desenvolvido nos cefalópodes. Menciona, também, os diversos gânglios nervosos que estão unidos entre si por cordões nervosos, ligados a nervos, os quais recebem informações dos órgãos dos senti- 
dos, tais como antenas, olhos e órgão do equilíbrio. Além disso, esse é o único material que menciona que os olhos do cefalópodes são comparáveis aos dos vertebrados.

Mesmo apresentando significativas diferenças entre si, todos os materias apresentam conteúdos que se assemelham ao apresentado por Ruppert e Barnes (1996), no que se refere à diferenciação da classe Cephalopoda.

Reprodução. A apostila A explica, de forma geral, a reprodução de algumas das classes, citando que bivalves, em sua maioria, são dióicos; cefalópodes são todos dióicos, e gastrópodes podem ser monóicos ou dióicos. Sendo que o desenvolvimento pode ser direto em gastrópodes terrestres, e indireto, com a formação do estágio larval, em gastrópodes aquáticos.

A apostila A e o livro didático representam, com ilustrações, as variações das formas larvais, porém, o livro didático é o único material analisado que descreve todo o processo de reprodução em molusco hermafrodita, mencionando as principais estruturas e suas respectivas funções para a realização deste processo.

A apostila B erra ao generalizar o hermafroditismo nos moluscos, além disso cita que, em cefalópodes, a fecundação é externa, com desenvolvimento direto, e, nos demais grupos, a fecundação é externa e o desenvolvimento indireto, através de larvas ciliadas. Embora correta, a informação de que os cefalópodes apresentam fecundação externa é incompleta, uma vez que a fecundação pode ocorrer tanto dentro da cavidade do manto, quanto fora. No entanto, independente do tipo de fertilização, sempre haverá cópula (RUPPERT e BARNES, 1996).

Ainda conforme constatado por Ruppert e Barnes (1996), os pulmonados terrestres são hermafroditas, sendo necessária a fecundação cruzada, com cópula e transferência mútua de espermatozóides. Os ovos são depositados dentro de envelopes,e o desenvolvimento é direto, exceto em algumas espécies marinhas.

\section{Importância dos moluscos}

Importância econômica. A apostila A é o único material didático que menciona a produção de pérolas nos Bivalvia, explicando, em uma figura, como se dá o processo de produção na cavidade interna do animal. Porém, a representação é complexa, dificultando seu entendimento.

Saúde Pública. A apostila A apenas menciona que alguns caramujos são hospedeiros intermediários de vermes, sendo que poderiam ser citados, como exemplos, os parasitos Angiostrongylus costaricensis, causador da angiostrongilíase abdominal, e Schistosoma mansoni, causador da esquistossomose. O livro didático e a apostila B apresentam falhas neste aspecto, e também desconsideram a importância alimentícia, econômica, ambiental e paleontológica. Contudo, o livro didático aborda parcialmente o assunto no capítulo "Biologia e Saúde".

Da mesma forma, nos materiais apostilados, a importância para a Saúde é tratada em outro capítulo, referente ao Filo Plathyhelminthes, considerando os parasitas que utilizam os moluscos como hospedeiros intermediários.

Visto que alguns alunos já apresentam um conhecimento prévio sobre o conteúdo tratado, verifica-se que os materiais didáticos analisados deveriam conter informações mais detalhadas acerca da importância do grupo, possibilitando, assim, ao aluno, relacionar o grupo estudado com o ambiente no qual vive, como é o caso dos problemas ambientais e econômicos associados à presença do mexilhão dourado, Limnoperna fortunei, nas instalações de usinas 
Santos, J. C. et al.

hidroelétricas e embarcações, o qual vem causando uma série de prejuízos materiais, além do desequilíbrio ambiental.

\section{Considerações finais}

Diante das falhas apresentadas, cabe ao professor adotar uma postura crítica na escolha do material didático a ser utilizado no estabelecimento de ensino. No entanto, podem ocorrer duas situações distintas vivenciadas no âmbito da escola em relação ao material didático adotado. Na escola com sistema apostilado, o professor é limitado aos conteúdos referentes às matérias básicas do Ensino Médio, e tem a obrigação de lecionar e terminar a tempo as aulas estabelecidas nos conteúdos programáticos. Sendo assim, o professor acaba não tendo espaço para contribuir com uma análise crítica em relação ao material didático trabalhado no estabelecimento de ensino.

Nas escolas em que o livro didático é adotado, a situação é contrária, o professor é tem oportunidade de efetuar escolhas, ficando a seu critério a busca por materiais mais atualizados e mais dinâmicos, sendo auxiliado, a partir de 2006, com a avaliação oficial do livro didático de Ensino Médio, realizada pelo MEC (BRASIL, 2006).

No entanto, tal fato nem sempre ocorre, pois os professores são desestimulados pelos baixos salários, excesso de alunos em sala de aula, falta de infra-estrutura escolar e apoio educacional, entre outros.

Como forma de minimizar os problemas decorrentes da falta de acesso às informações corretas e atuais, os autores dos materiais analisados deveriam ser mais criteriosos, apresentando não somente aspectos da morfofisiologia de cada classe do Filo Mollusca, mas também a relação que estes animais possuem com o meio em que vivem, inclusive com o homem, tal como é enfatizado dentro do conteúdo dos Parâmetros Curriculares Nacionais (PCN) (BRASIL, 1998).

Uma outra ação deve ser focada na utilização do material de apoio representado por livros paradidáticos (que o professor deve conhecer e recomendar a leitura), além de CDROM, que, em muitos casos, acompanham as apostilas.

Contudo, é necessário que as escolas sejam mais bem preparadas, com acervo bibliotecário atualizado e microcomputadores com acesso à rede Internet, e possibilidade de leitura de mídia digital.

Nesse sentido, a despeito de grande parte das escolas particulares oferecerem esta possibilidade aos alunos, na rede pública, vê-se a subutilização de tais equipamentos, sobretudo pela falta de professores capacitados para utilizarem o computador e, conseqüentemente, a rede Internet como ferramenta de acesso à informação, sendo incapazes de recomendar ou não o acesso a determinados "sites", e, na seqüência, explorar o conteúdo em sala de aula. Assim, é preciso que o educador se conscientize do seu papel social e sofra uma mudança na postura do professor, e, assim, deixe de agir de forma a contrariar o processo educativo, que vai além dos conteúdos ministrados em sala de aula. 
Análise comparativa do conteúdo Filo Mollusca...

\section{Referências}

AMABIS, J. M.; MARTHO, G. R. Fundamentos da biologia moderna. 3. ed. São Paulo: Moderna, 2002.

BELMIRO, C. A. A imagem e suas formas de visualidade nos livros didáticos de Português. Educação \& Sociedade, Campinas, v. 21, n. 72, p. 11-31, 2000. Disponível em: < http:// www.scielo.br/pdf/es/v21n72/4191.pdf.>. Acesso em: 24 set. 2003.

BIZZO, N. Graves erros de conceito em livros didáticos de ciência. Ciência Hoje, Rio de Janeiro, v. 21, n. 121, p. 26-35, 1996.

BRASIL. Portaria, n. 501, de 14 de fevereiro de 2006. Diário Oficial [da] República Federativa do Brasil, Poder Executivo, Brasília, DF, 15 de fev. 2006. Seção 1. Edição número 33. Disponível em: <http://portal.mec.gov.br/seb/arquivos/pdf/ port501_pnlem.pdf.>. Acesso em: 09 mai. 2006.

Secretaria da Educação Fundamental, Ministério da Educação. Educação Fundamental - Projeto de Avaliação de Livros Didáticos de $1^{\text {a }}$ a $8^{\text {a }}$ Série, p. 1-7, 2000. Disponível em: <www.mec.gov.br/sef/fundamental/avalidid.shtm>. Acesso em: 22 abr. 2005.

Câmara da Educação Básica, parecer CEB 15/98, aprovado em 1/6/98 (Processo 23001.000309/97-46). Diretrizes Curriculares Nacionais para o Ensino Médio. Disponível em: <http://www.etfce.br/Ensino/Cursos/Medio/parecerCEB15.htm>. Acesso em: 15 jun. 2005.

LIMA, M. R. Construção e validação de instrumento de avaliação do livro didático de estudos sociais. Tecnologia Educacional, Rio de Janeiro, n. 60, p. 57-68, 1984.

RUPPERT, E. E.; BARNES, R. D. Zoologia dos invertebrados. 7. ed. São Paulo: Roca, 2005. ; _ _ 6. ed. São Paulo: Roca, 1996.

SILVA, E. R. L. S. Análise de conteúdo dos Artrópodes em livros didáticos do Ensino Médio em Cascavel, PR - um estudo de caso. 2002. 48f. Monografia (Conclusão de Curso em Ciências Biológicas) - Universidade Estadual do Oeste do Paraná, Cascavel, 2002. 
Santos, J. C. et al.

\section{ANEXO 1}

\section{ROTEIRO PARA A ANÁLISE DE MATERIAL DIDÁTICO ASPECTOS GERAIS E ESPECÍFICOS}

\begin{tabular}{l} 
ASPECTOS GERAIS \\
\hline 1. Capa com cores, motivos e aparências capazes de despertar a atenção do aluno. \\
\hline 2. Encadernação (boa qualidade, resistente ao manuseio e transporte). \\
\hline $\begin{array}{l}\text { 3. Espaço entre linhas, que permite a leitura com facilidade e hierarquização de títulos e } \\
\text { subtítulo. }\end{array}$ \\
\hline 4. Tamanho das letras facilitando a leitura. \\
\hline 5. Ilustrações (desenhos, gravuras, fotografias, mapas, gráficos) e correções. \\
\hline 6. Quadros e tabelas descritivas ou comparativas. \\
\hline 7. O custo do livro didático. \\
\hline ASPECTos Do conTEúDo \\
\hline 1. Conceitos gerais e específicos. \\
\hline 2. Forma de apresentação do conteúdo. \\
\hline 3. Presença de textos complementares e interdisciplinares atualizados. \\
\hline 4. Grau de atualização do conteúdo. \\
\hline 5. Presença de atividades complementares (questões de vestibular, leitura recomendada etc). \\
\hline
\end{tabular}

Artigo recebido em fevereiro de 2007 e aceito em julho de 2007. 